\title{
Gênese da Notação Musical na Criança* os signos gráficos e os parâmetros do som
}

\author{
Pedro Paulo Salles
}

I

O presente estudo nasceu do desejo de sistematizar e interpretar as idéias, os processos e os resultados de um trabalho, realizado com crianças de 6 a 11 anos, em sala de aula, que visava ao delineamento de uma pedagogia musical, cujo desdobramento em direção a uma gênese da notação musical na criança - é um de seus aspectos mais interessantes e originais, não só devido aos processos articulados pelas crianças, que possibilitaram uma visibilidade do invisível, processos próprios da imaginação e de seu desenvolvimento na criança - mas principalmente aos possíveis musicais que se abrem, num crescendo, à criança, favorecendo-a tanto no plano do intelecto e da construção, como também no plano da intuição e da imaginação criadora. Embora saibamos que, para alguns, a escrita musical possa parecer precoce às crianças desta faixa etária e até mesmo um impedimento ao desenvolvimento de uma fruição criadora, procuramos demonstrar - sem fazer uma apologia da notação musical - que, na gênese da própria música na criança e no processo de construção do conhecimento musical, notações de diversas naturezas acompanham essa gênese em

* Este artigo é baseado em capítulo da dissertação de mestrado Gênese da Notação Musical na Criança, apresentada pelo autor à Faculdade de Educação da USP, sob orientação do Prof. Dr. Celso Fernando Favaretto. 
complexidade crescente, como um dado ligado não exclusivamente ao seu aspecto de tradução visual, mais ou menos intelec-tual ou puramente perceptiva de uma vitalidade sonora, mas sim à possibilidade de penetração cognitiva e também intuitiva na materialidade da música, que supõe signos e mistério .

O trabalho aconteceu como experiência em sala de aula, entre os anos de 1978 de 1989, assumindo um caráter de pesquisa, interessada na elaboração de novas bases para uma metodologia de ensino musical. A dinâmica do trabalho em sala de aula compreendeu situações coletivas e individuais de percepção, exploração, improvisação, composição, criação de grafias; análises, discussões, registros diários das descobertas feitos pelas crianças; debates, reflexões e questionamentos. O processo visava sempre à construção gradativa da linguagem musical pelas crianças. O código gráfico para os sons, tal como se deu na história da música, aparecia nesse processo, ora como instrumento gerado por necessidades, ora como deflagrador de novos avanços.

Trata-se agora de processar e interpretar os dados observados naquela experiência, inclusive a partir de alguns pressupostos da teoria psicogenética de Jean Piaget.

O recorte aqui operado destaca algumas articulações e artimanhas gráficas e conceituais de diferentes grupos de crianças na representação do som, tendo como objeto analítico os parâmetros dos som, ou seja, intensidade, altura e timbre. Pode-se dizer que estaremos, então, observando o "comportamento" de diferentes formas gráficas diante da representação de cada um destes parâmetros.

\section{II - A Natureza da Notação Musical ${ }^{1}$ e o Ensino}

O ensino tradicional de música apresenta, para a criança, um repertório limitado e pré-determinado. A notação musical, que necessariamente está vinculada a esta escolha de sons, é introduzida diretamente por meio da imitação, numa verdadeira injeção, uma "aquisição" mecânica sem vivência e pensamento. Poucas vezes 
questiona-se o tipo de aquisição da criança, diante destes sons e de sua notação, e mesmo se estaria havendo alguma.

A história da música, não só da chamada música ocidental, tida como "oficial", mas também da música de outras culturas e civilizações, como a oriental e a indígena, mostra uma grande riqueza naquilo que poderíamos chamar de os possíveis da música: uma imensa variedade na natureza das descobertas, nos códigos, na visão de música, nas escolhas sonoras e na notação musical. Por que uma tal gama de possíveis não comparecem nas propostas de ensino de música? Se o homem, ao longo das eras, pôde traçar tantas trilhas e abrir tantas clareiras epistemológicas, deverá a criança ficar à parte dessa aventura do conhecimento? A liberdade e a objetividade necessárias para a exploração, a descoberta, e a construção do conhecimento sonoro e musical lhe são negadas em favor da obediência e da ação repetitiva ou exploratória sem sentido. Restam músicas esqueléticas e uma notação revestida de sons sem vida. $O$ constante procedimento imitativo no ensino da leitura da notação vem, então, esvaziando os signos gráficos de significado e a metodologia de inteligência e sensibilidade. Os signos gráficos musicais, que devem ser mediadores de uma relação viva entre o homem e a música, símbolos de vida, aparecem como significantes dissociados dos significados e dos referentes (os sons), o que produz na leitura a dissociação entre música e significação. Dessa forma, o sinal gráfico nunca será signo, que é sua função real $^{2}$.

"Enfatiza-se de tal forma a mecânica de ler o que está escrito, que se acaba obscurecendo a linguagem escrita como tal. Ao invés de se fundamentar nas necessidades naturalmente desenvolvidas nas crianças, e na sua própria atividade, a escrita lhes é imposta de fora vinda das mãos dos professores (...) como por exemplo o tocar piano. O aluno desenvolve a destreza de seus dedos e aprende quais teclas deve tocar ao mesmo tempo que lê a partitura; no entanto, ele não está, de forma nenhuma, envolvido na essência da própria música"3. 
Cria-se um conflito, pois, entre o decifrado da notação e a obtenção de seu sentido. O resultado é desatroso. Pois, apesar de o código estar pronto e já supersignificado na cultura ocidental, a criança não adere. Para ela, deve vir primeiro o som, ou melhor, a busca de um som. Como perseguidoras do som, as crianças investem as notações de sentido e, assim, igualmente, a matéria sonora. É na atuação da criança sobre a materialidade mesma dos sons, ou do espaço sônico, que são gerados, pois, as significações e os primeiros conceitos. No caso, o som não será imitado ou reprovocado devido a meros estímulos unilaterais, mas sim porque, por algum motivo, um determinado som ou uma determinada coleção de sons adquirem sentido.

Pode-se dizer que a notação tradicional em sua utilização errônea têm sido um dos obstáculos mais firmes diante de um progresso da criança na aquisição da linguagem musical. Quantos anos, vamos imaginar, necessita uma criança para "dominar" a técnica de um instrumento e o código musical, até que ela possa, finalmente, criar aquela música que pulsava em seu desejo no início de tudo? Quatro, seis, oito anos? E será que ela, após todo esse tempo, supondo que ainda não tenha desistido de aprender música ou que não tenha sido afetado seu prazer e seu gosto pela música, vai-se lembrar, finalmente, daquela primeira idéia sonora ou musical?

Assim, o ensino da música - considerada como uma estrutura fechada de conceitos e técnicas ou como um código arbitrário, tanto de condutas, como de materiais sonoros e grafias - já o salientamos, trabalha com formas prontas, "muitas vezes impróprias para exprimir as necessidades ou as experiências vividas do eu. É, portanto, indispensável à criança que ela possa dispor igualmente de um meio de expressão próprio, isto é, de um sistema de significantes construídos por ela e dóceis às suas vontades"4.

Por isso, a compreensão da natureza da notação musical parece-nos fundamental. E tal compreensão não é possível a não ser a partir de uma aproximação dos estágios iniciais da história da notação e de sua psicogênese. 
Assim, se na história, a invenção das grafias musicais não foi gratuita ou casual, mas para responder a necessidades específicas surgidas historicamente no complexo desenvolvimento dos sistemas de sons e das composições musicais, e no arco semiótico de cada cultura em que foi engendrada, do mesmo modo ocorreu no trabalho com as crianças. Procurou-se desenvolvê-lo de maneira que a notação fosse também uma necessidade interior e não exterior, essencial e não gratuita, social e não autoritária.

O número cada vez maior de sons simultâneos articulados nas composições das crianças e a elaboração igualmente progressiva de suas estruturas demandarão uma constante discussão dos signos gráficos, na sua constituição interna e enquanto organização espacial e visual da partitura. Ambos, composição e notação, estarão ligados num jogo de reciprocidades. Assim, a influência da notação na composição também ocorre, pois, se a notação é um conjunto de técnicas operatórias, implica no conjunto de procedimentos da música. Semelhante articulação se observa, por exemplo, na polifonia, cuja elaboração e evolução teriam sido impossíveis sem os instrumentos gráficos, que permitiam um domínio sobre a matéria sonora antes nunca imaginado.

Se aprendemos com a história que momentos diferentes, necessidades diferentes, culturas diferentes e ambientes sonoros diferentes geraram músicas e notações igualmente diferentes, nas quais o conceito de precisão, por exemplo, era totalmente outro, devemos nos perguntar sobre a aplicação de notação musical no trabalho em educação musical com crianças, considerando as especificidades desse trabalho e a natureza das relações da criança com músicas e sons.

\section{III - Os Signos Gráficos e os Parâmetros do Som}

Neste artigo, pretendemos mostrar as implicações dos parâmetros do som - intensidade, altura e timbre - na invenção dos signos pela criança e na constituição de sua dinâmica.

Para que o leitor se oriente na discussão que ora é apresentada, é necessário colocar de antemão as notações criadas pelas cri- 
anças; segundo o estudo realizado, elas se constituem dos seguintes tipos: a pictografia musical (principalmente desenho da fonte sonora, desenho de imaginação - descrição figurativa e simbólica), a notação lingüística (descrição verbal e onomatopéia - escrita), a notação plástica (desenho "abstrato") a notação analógica (linear e geométrica - grafismo) e as notações mistas.

\section{INTENSIDADE: a retórica do trovão e do segredo}

Nas grafias, a intensidade e a altura percorrerão um caminho que vai do figurativo à abstração, da noção de estados estanques até à de transformação. Suas hipóteses acerca da representação dos sons fortes e fracos, também irão girar entorno do conceito de presença ou de proximidade. Veja-se, a título de exemplo, esta pictografia, este desenho de imaginação:

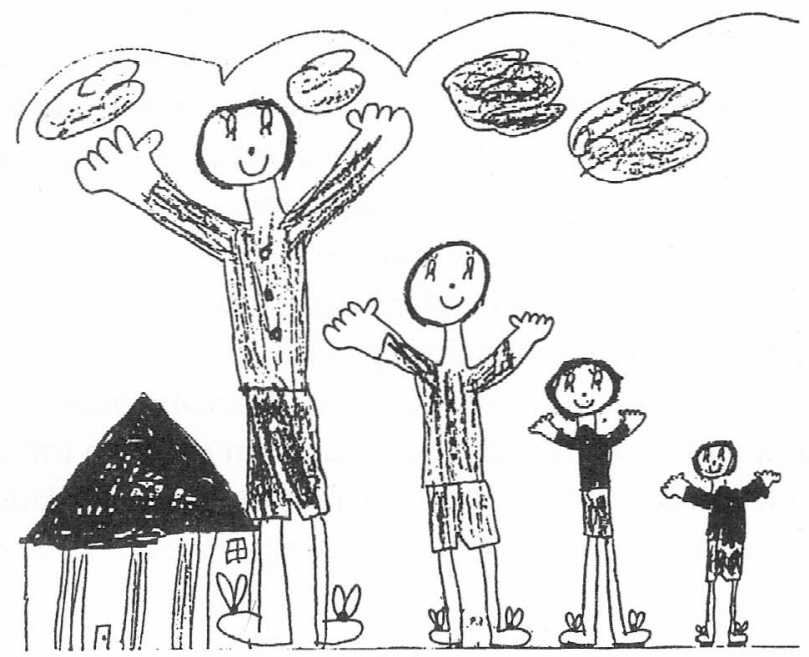

Calima, 8 anos - um crescendo (lê-se da direita para a esquerda)

Há, pois, uma forte relação entre a intensidade do som e sua presentificação. Talvez a intensidade seja, em função disso, um dos parâmetros mais próprios e característicos do som em si, pois determina, através de suas flutuações, a própria sensação (auditiva e tátil) 
da presença do som nos domínios do espaço e do silêncio. Aí, a intensidade se confunde com a própria vibração sonora, em que a noção de som forte e som fraco é análoga à de som e silêncio.

É comum nas terminações de movimentos, a música ir diminuindo em intensidade até o silêncio; assemelha-se a um afastamento das fontes sonoras até seu sumiço na distância, como se a orquestra, ou o conjunto, estivesse se afastando do ouvinte, levando a música a um estado de ausência. Em certas partituras tradicionais, tal procedimento é mesmo explicitado como descrição qualitativa da intensidade: lejano, morendo, sumindo, lontano etc.

A noção de intensidade como presença se confirma ao repararmos que um aumento de intensidade é chamado de "crescendo". O crescendo é uma das formas mais primitivas de intensidade e se articula nas improvisações coletivas com instrumentos, como busca da sensação de presença, ou melhor, do poder de produzi-la. O prazer no som como presença acontece em diferentes idades, inclusive em grupos de jovens, nos contatos primevos com a música como improvisação. O inverso, isto é, a diminuição de intensidade (dimimuendo ou decrescendo), acontece com menor freqüência e é localizada nas terminações, ainda de forma intuitiva. A intuição é aí entendida como uma forma de escuta ativa, guiada pelo que Piaget chamou de pensamento intuitivo, que, neste caso, por uma força só percebida no social, no coletivo, parece dar conta das transformações, além dos estados inicial e final.

Assim, inversamente ao movimento em direção a um infinito de intensidade, a um fortíssimo idealizado, vê-se que a busca do infinito da intensidade em direção a um pianíssimo e a um silêncio idealizados, ocorre com menos freqüência. Este movimento depende tanto de uma sintonia como de uma construção, ou de uma reconstrução, que Piaget chamou de reversibilidade. O padrão instintivo inscrito no grupo se desenvolve para uma consciência das transformações, torna-se aprendizado.

Se, por um lado, aliamos a intensidade à idéia de uma presentificação e de uma proximidade do som, principalmente pelo impacto dos sons fortes e dos crescendos, e também por ser o som 
forte o primeiro a ser percebido pela criança, por outro lado, o som fraco demanda maior trabalho, depende de uma experiência da criança com a sociabilidade - de tal modo que o som do outro seja ouvido - e com o silêncio - de tal modo que a presença microscópica de um sussurro seja tão impactante quanto à de um trovão. Daí a idéia, também, do silêncio como presença.

Então, a vivência da leveza e do mistério de se ouvir sons em fraquíssimo, de que a criança tira prazer, mostra-se também fundamental. Observa-se, por exemplo, como ao produzir um som o mais fraco possível ela gosta de partilhar com outras. Certa ocasião, uma menina de sete anos entrou na sala de aula e disse: "Pedroô, eu tenho um som! Mas preciso do máximo de silêncio." As outras dezesseis crianças e eu fizemos, então, um silêncio sepulcral, não se ouvia um nada de coisa alguma. Construído esse microcosmos de silêncios, cúpula para ressonâncias, a menina de longos cabelos castanhos retirou, lenta e cuidadosamente de sua mochila uma escova de cabelos: a situação era para pasmos e suspensões. Então, de ouvidos e olhos arregalados e de respiração suspensa, pudemos perceber a lenta, leve e repetida respiração do escovar.

Mímica: mínima música.

Cabelos tangidos em movimentos precisos, gestos sem gravidade regendo intensidades, movendo significações pelo ar. Diante de nós, toda a música: intensidade (presque-rien), duração ( $c a-$ belos longos: som longo), timbre (fricção), densidade (os fios da chevelure) e mistério. Formado em grande parte por silêncios, o escovar é quase um som conceitual e evoca as levíssimas brumas de Debussy e as filigranas timbrísticas de Webern. Se o som fraco retém um alto índice de silêncio relativo (no exemplo vimos um som-quase-silêncio), e o som forte retém um baixo índice de silêncio relativo (e um alto índice de som), talvez a intensidade compreenda três graduações em sua dinâmica: som forte, som fraco e silêncio; vendo o silêncio como um produtor 
de intensidades. E, na lógica da distância, quanto mais se distancia uma fonte sonora imaginária, mais fraco é o som, até o limite ou infinito que resulta em silêncio: o infinito da intensidade.

Este jogo, no trabalho de música com crianças, é um campo rico para se desenvolver a noção de intensidade. Além disso, o trabalho de criação musical supõe a articulação de intensidades.

Embora, na experiência com crianças, o crescendo tenha-se mostrado como forma primitiva de intensidade, já na história da música ocidental as graduações mais acentuadas são bem tardias. Pouco utilizadas no século XVII, as indicações descritivas crescendo e dimuniendo só aparecem marcadamente no período da música clássica. No fim do século XVIII, a orquestra de Manheim impressionava por suas interpretações, notadamente a interpretação das intensidades. O mestre de capela de Berlim, J.F. Reichard, narra como foi a primeira vez em que o maestro Niccolò Jommelli utilizou o crescendo e o diminuendo; sua descrição do ouvinte nos confirma que o crescendo é aproximação assoladora e o dimimiendo $e ́$ distanciamento, perda e suspensão:

"A primeira vez que Jommeli utilizou o crescendo, o público se levantou literalmente de seus assentos. Logo ao chegar no dimimuendo seguinte, os ouvintes quase não respiravam". ${ }^{5}$

A presentificação do som é, pois, estabelecida por um jogo entre intensidade e percepção, permeadas pela sensação de distância. Assim, do ponto de vista do receptor, som forte = emissor próximo, e um mesmo som fraco $=$ emissor distante; em contrapartida, o ponto de vista do emissor torna-se dependente do sujeito e, por isso, subjetivo e imprevisível. A música se serve de ambos.

Do mesmo modo, quando uma criança quando está brincando com bonequinhos, ela imita vozes, ruídos e suas intensidades. Assim é que, surpreendentemente, sons originalmente fortes, como 
palavras mágicas, tiros, trombadas, gritos de dor ou a vibração da torcida após um gol, são reproduzidos vocalmente pela criança como se viessem de longe. Ela emite os sons com intensidade menor, mas os redimensiona de forma que pareçam sons fortes ao longe. Procedimento semelhante se observa em determinadas composições das crianças, quando certas frases musicais se repetem em eco, isto é, com a intensidade mais baixa do que a frase original; a diferença entre a emissão (forte) do som e a recepção (fraca) do eco dá a impressão de uma terceira dimensão na música: espacializando-a pela noção de eco - ou distanciamento - e temporalizando-a pela recorrência e pela memória. ${ }^{6}$

Já quando a própria criança encarna as personagens, os sons tendem a assumir a intensidade original de sua emissão. $O$ significado desta diferença pode estar no simples fato de que os bonequinhos são pequeninos, estão no plano baixo, ao passo que a criança que os manipula é como um gigante no plano alto. Então, a distância relativa à diferença de tamanho e de plano pode levar a criança a transformar o som original em um som mais fraco.

Vejam-se estas descrições, a primeira em uma história sonora (descrição simbólica) e a segunda em uma composição (descrição direta):

Elefantes andando junto com o passarinho passarinhos param de cantar Elefantes começam a urrar Um vento bem forte

Os passarinhos voam, os patinhos ficam assustados e começam a bater o pé na água e a fazer qüém qüém e acaba com um vento fraquinho. (história sonora, 7a)

(OBS: Nesta história sonora, o apito e a gaita representam o passarinho, o tambor representa o elefante, o tambor e o reco-reco representam os patinhos, a flauta representa o urro dos elefantes, o apito representa $o$ vento e outro tambor representa o vôo dos passarinhos.) 
Revista Música, São Paulo, v.7, n.1/2: 149-183 maio/nov. 1996

159

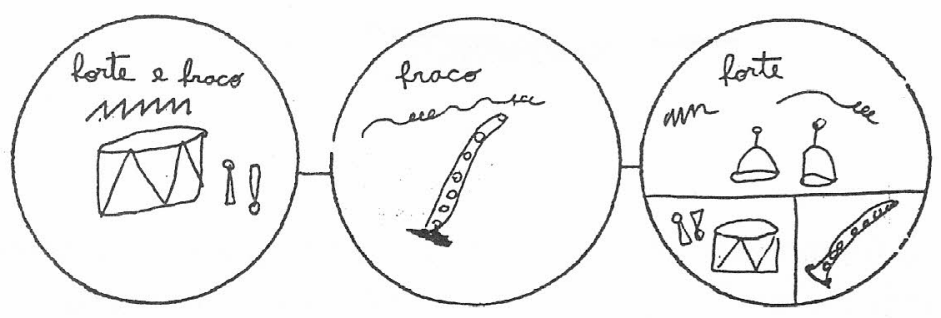

Composição, $8 a$.

Como se vê, no início a criança busca imagens ou signos que já conhece para representar um som mais forte ou mais fraco, utilizando então desenhos ou escrita.

Já na onomatopéia, na notação plástica e na notação analógica, uma analogia entre a noção de presença (ou proximidade) do som e o tamanho do signo, também se dará: som mais forte $=$ mais próximo (portanto signo maior), som mais fraco $=$ mais distante (portanto signo menor).

tcham, tcham, tchorm tcham, tcham, tchoum

Marcos Baiá, 9

(1) Rafa chebid

Lurrida

ORicardo tavabem!

turn a

a sis á tonta

Q Varessa tarabém!

Tiago, 9 


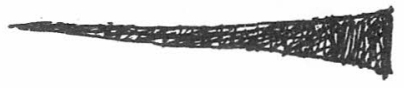

Juliana, 7

O último exemplo representa as transformações da intensidade, tradução gráfica que é do crescendo e do dimunuendo, mencionados no início. Tal signo é também utilizado nas partituras tradicionais sob a forma diagramática $<$.

A notação plástica e a notação analógica ainda usam três outros expedientes para representar as variações de intensidade do som: a intensidade do traço (linhas mais calcadas e nitidas representam os sons mais fortes, e linhas mais apagadas ou fracas, os sons mais fracos, onde a analogia é articulada pela idéia de uma força empregada na produção da intensidade, tanto do som, quanto do traço),

a cor do traço ou do espaço pictórico (em que as cores quentes ou as de tons mais escuros representam sons mais fortes, e as cores frias ou as de tom mais claro representam sons mais fracos),

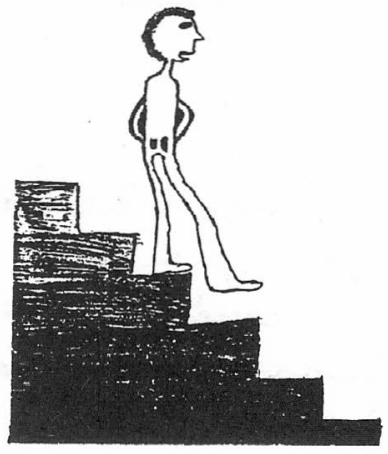

Fernando, 8

e o movimento ou direção do traçado (em que sons fracos são a linha em repouso horizontal, e os sons fortes são momentos de 
verticalidade mais intensa, quase como um eletrocardiograma ou, como se passou a chamar na notação contemporânea, "grafismo"; analogamente, observe-se o segundo exemplo, em que a seta para cima indica o forte, e para baixo o fraco).

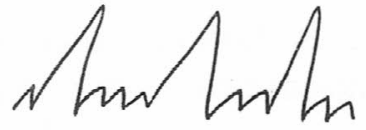

Maria, 7

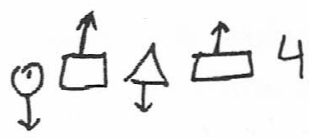

Douglas, 8

Não raro, há também a noção de som pesado e som leve, ora se referindo à intensidade, ora à altura e ora à igual fusão. Seu resultado gráfico se iguala ao do traço mais ou menos intenso modulado por uma força ou peso.

Mais rara é a intensidade representada, na notação analógica, por uma linha ascendente e descendente. Essa "invasão" da intensidade, na área da altura e da melodia, ocorre em razão de uma conceituação natural das crianças, oriunda da linguagem comum, na qual "som alto" e "som baixo" não se referem, particularmente, nem à intensidade nem à altura, mas à sua fusão. Assim, "som alto" é agudo e forte, e "som baixo" é fraco e grave. Esta noção tem duas razões: a primeira é vocal, ou seja, é mais fácil emitir um som forte no registro agudo e um som fraco no registro grave; a segunda, diz respeito à percepção dos fenômenos físicos; um som mais agudo, como se sabe, é produzido por vibrações mais rápidas; é fácil percebermos isso observando as modulações de intensidade e altura de um automóvel: ao ligarmos o motor, seu som está grave e fraco; é possível mesmo ouvir cada vibração, de tão lentas; ao acelerarmos, o som fica mais agudo e também mais forte, até o limite de um fórmula I: rapidíssimo, agudíssimo e fortíssimo.

Tais conceituações (alto/baixo), que Piaget chamou de "sincretismo incoerente", se não se incluem nas cartilhas da música, estão todas estampadas nas partituras tradicionais pois, via de 
regra, a intensidade é sugerida por descrições igualmente simbólicas e metafóricas.

\section{ALTURA: montanha russa}

O princípio do desequilíbrio e da dualidade rege o som no contínuo da altura. Entre os extremos desse contínuo, o grave e o agudo, flutua o som em zig-zag. Já se mencionou no final do item anterior a "melodia do automóvel", as modulações de potência e de velocidade produzindo desde o grave ruidoso e descontínuo até o agudo contínuo.

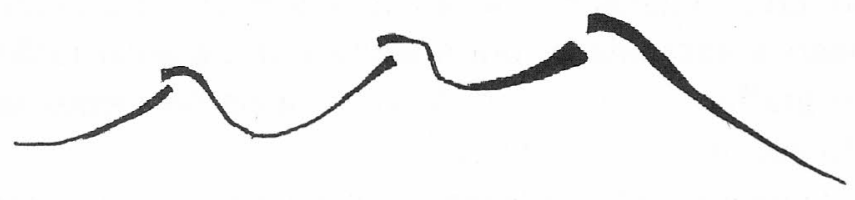

A melodia do automóvel - Christian, 8

A percepção traz à consciência outros fenômenos físicos regidos pelo mesmo princípio; o conhecido e denotado som "porta rangendo", por exemplo, tem seu charme graças a ele. Seu ranger oscila entre os sucessivos estalos no grave (abrir lento ) e a linearidade do agudo (abrir mais rápido ); daí o seu "nhéééééc", sua terrível prosódia em voz de bruxa. Estas leituras do real fazem ver a ludicidade na acústica; a importância da captação desta ludicidade na explicação dos sons às crianças, é extrema. Se, de fato, elas gostam tanto deste som que até o reproduzem, tecem também variações: fazem com a voz um som "o mais grave possível", a ponto de se perceber a seqüência de estalos das cordas vocais, qual rangido de porta de castelo, qual ronco de um velho motor.

A experiência da altura leva a criança a traduzir as flutuações percebidas em flutuações gráficas, e o princípio da dualidade pede a definição dos extremos na grafia. Agora, se o contínuo é recorta- 
do em determinadas porções, será necessária a definição gráfica destas porções e de suas relações.

$\mathrm{Na}$ onomatopéia, a altura é representada de duas maneiras: na oscilação para cima e para baixo, tal como na notação analógica, e, mais comumente, na variação de vogais. A propósito disso, observem-se os registros de uma criança, a partir de ditados sonoros compostos por seus próprios colegas:

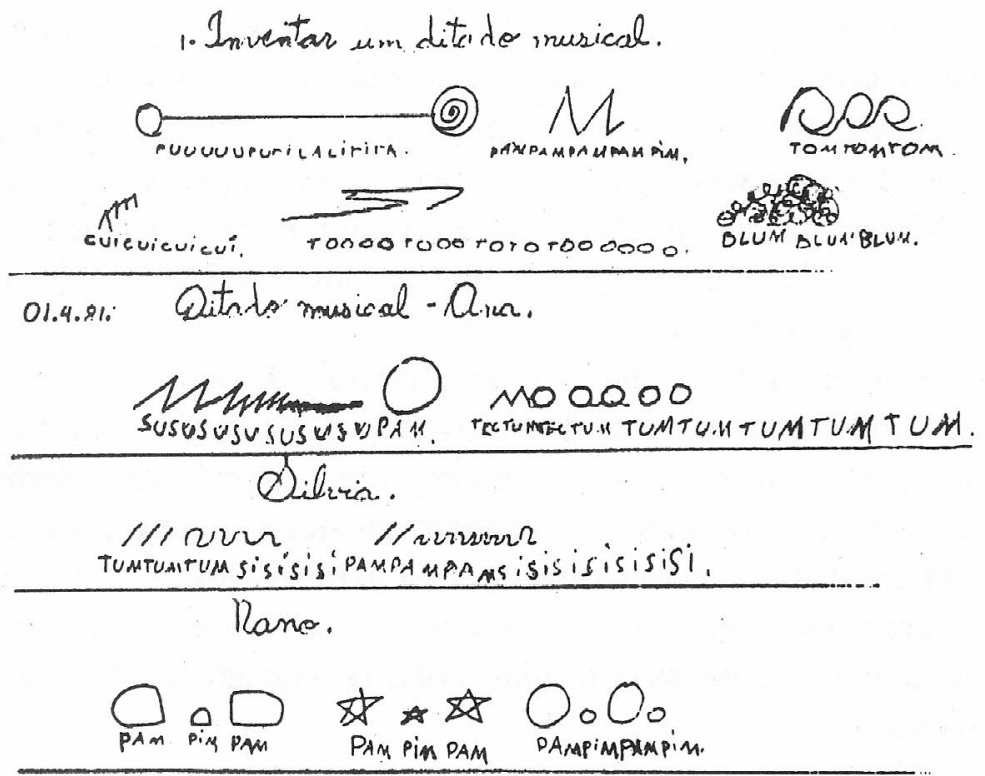

Camila, 7a. 1980

Em sua elaborada notação polynomial (ou mista) para os sons instrumentais, cuja invenção (gênese) vemos no primeiro trecho, que é o ditado de sua autoria, a onomatopéia revela-se ambígua, pois representa timbre e altura segundo o mesmo critério: morfemas com " $\mathrm{i}$ ", tanto para representar sons agudos quanto para sons metálicos: "Sissi", tim", "pim" etc.; e morfemas com "o" ou com "u", tanto para sons graves quanto para sons de tambor: "Tom", "tooo", "tum". Tal associação entre diferentes dimensões do som é 
comum e é representada em inúmeros exemplos gráficos das crianças. Resumindo, as alturas estão contidas nos morfemas - "i", "a" e "é" para os sons mais agudos e "o", "ê" e "u" para os sons graves. Esta motivação do signo também ocorre, embora de forma invertida, na composição de canções, quando as vogais contidas nas palavras motivarão sons mais agudos e mais graves na melodia.

Na notação plástica, as alturas aparecem representadas por cores e texturas, naquilo que elas têm de timbrístico. Seria muito dificil determinar taxativamente as constâncias na escolha das cores, já que outros fatores que compõem o som - timbre, intensidade, melodia, sucessão, andamento, percepção subjetiva, etc. - também influem na escolha das cores e do traço na representação dos sons; mas pode-se dizer, genericamente, que as crianças vêem nos sons mais graves matizes do preto e do azul e, nos sons mais agudos, matizes do vermelho e do amarelo. Quando a escolha de cores é arbitrária ao invés de motivada, sua relação com o som ouvido pode ocorrer após o desenho pronto, quando seus elementos são, então, investidos de imagens musicais. Este é o caso de grafias criadas por crianças de 9 anos para as alturas, em que as cores eram escolhidas arbitrariamente para a gama de alturas da flauta; sob as partituras coloridas, bulas revelavam as relações determinadas.

Além disso, a notação plástica aponta também para a constituição da notação analógica, na medida em que suas variações de traçado, ascendente e descendente, sugerem as flutuações de altura.

Se o desenho da fonte sonora, por sua vez, dificilmente poderá representar a altura em razão de sua falta de mobilidade - a não ser no caso de fontes sonoras já conhecidas por seus graves e agudos - , já o desenho de imaginação poderá, através da metáfora, fazê-lo. Assim, não raro, as crianças representam um som grave com o desenho de um "elefante" e um som agudo com o de um "pintinho", num princípio semelhante ao da representação das intensidades forte e fraca. 

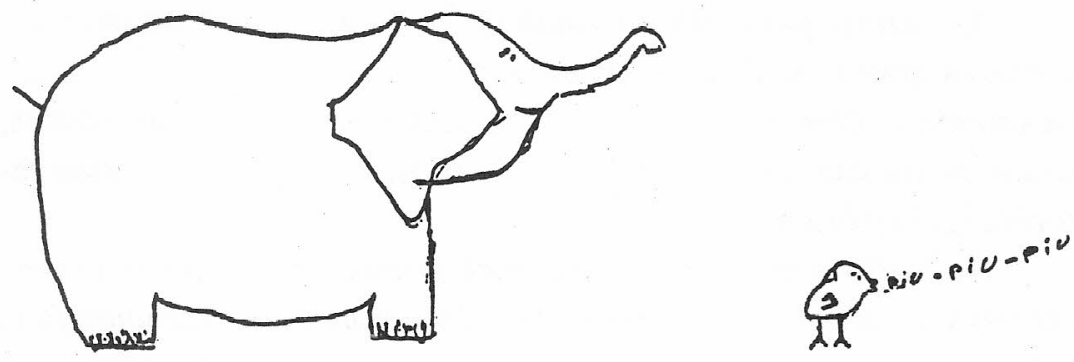

Patricia, 9 - forte e fraco

Há nesta metáfora certa sapiência: sons graves são emitidos por materiais mais elásticos, geralmente grandes, e sons mais agudos por materiais menos elásticos, geralmente menores. Por isso, há um equívoco quando, em certos filmes, um homem que diminui até ficar do tamanho de um.polegar continua falando com a mesma voz grave, quando deveria, na verdade, passar a falar com voz finíssima, agudíssima, como no correto final de $A$ mosca da cabeça branca (The Fly, EUA, 1958), filme de Kurt Newmann.

Também no desenho de imaginação ocorre a base da notação analógica: a analogia entre as inflexões da altura e a ascenção e descenção dos signos gráficos. Nos desenhos de imaginação, esta característica diastemática está referenciada a elementos visuais com variações topográficas ou com movimentos ondulatórios: escada, escorregador, montanha, subida e queda, cobra, onda, tobogã, montanha russa, etc.

A título de exemplo, notem-se na página seguinte uma série de grafias feitas a partir de um assobio em glissando descendente (som contínuo em direção ao grave):
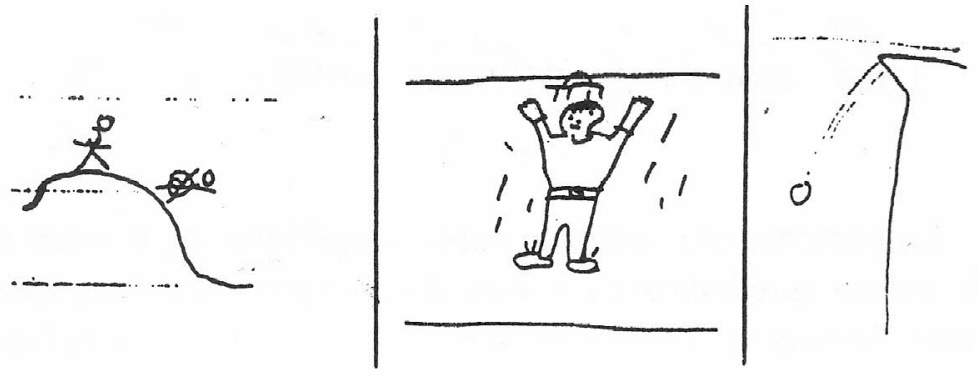
As razões para esta analogia já foram aventadas no capítulo sobre as grafias analógicas; trata-se, agora, de observarmos analiticamente o đesénvolvimento desta grafia no âmbito das alturas, sua importância no desenvolvimento musical da criança e suas referências históricas.

$\mathrm{Na}$ história da música, a evolução deste tipo de notação percorreu três etapas: primeiro a notação ecfonética, caracterizada pelo uso com fins musicais dos acentos criados pelo gramático alexandrino Aristophane de Bizâncio (século III a.C). ${ }^{7}$ Os acentos foram o ponto de partida para todas as notações orientais que se conhecem, à exceção da do Islam; assim é que as notações ecfonéticas armênia, hebraica, síria, etíope, egípcia, e outras ora indecifráveis, derivam destes signos prosódicos bizantinos.

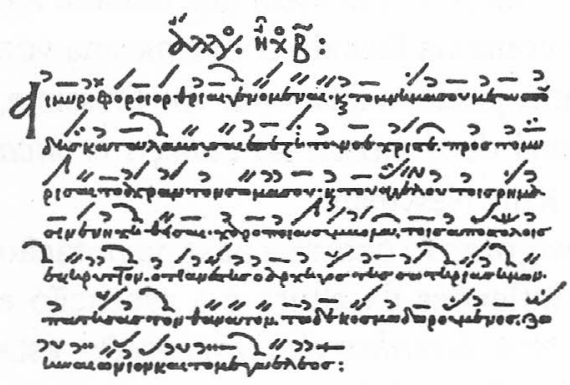

Notação ecfonética: paleobizntina - séc. X

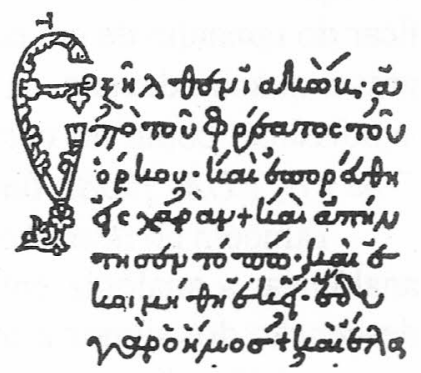

Grega

A segunda etapa se caracteriza pela notação neumática (século IX), que teria sofrido influência da notação ecfonética e também da prática da quironomia, que consistia em acompanhar as variações melódicas do canto com um código gestual.

$$
\begin{gathered}
\text { Liff. cua deuf refornet coram ze rex } \\
\text { séc. } I X
\end{gathered}
$$

Largamente utilizados no canto gregoriano, os neumas são, pois, signos que indicam a direção do contorno melódico, sem no entanto determinar a altura exata e a duração dos sons. Em função 
destas deficiências, os neumas serão acrescidos de outros signos, como os da notação alfabética, no sentido de precisar as alturas e os intervalos. Mas uma transformação mais radical estava por vir; o aparecimento da notação diastemática iria dar o tom da notação tradicional. Numa terceira etapa, então, aparece a notação diastemática. Ela se caracteriza pela colocação dos neumas mais acima ou mais abaixo, para representar as oscilações melódicas.

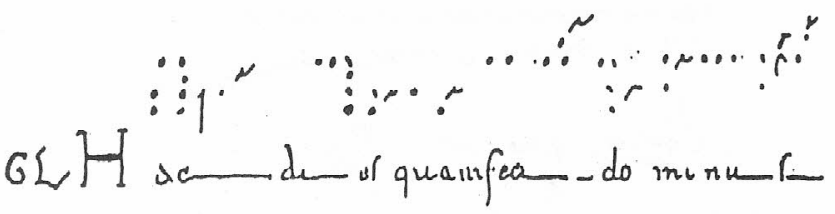

séc. $X I$

São inúmeros os exemplos de notação neumática e diastemática das crianças. A descoberta deste gênero de escrita musical lhes possibilita uma manipulação mais ágil do som, seja na composição, seja na percepção, seja na leitura. Sua compreensão visual é quase imediata e, por suas analogias motivadas e por sua concisão, torna mais evidentes os contornos melódicos. Na composição de canções, a notação analógica neumática vem substituir uma pictografia, que se limitava a representar, pleonasticamente, os conteúdos do texto. Como instrumento para composição de canções, ela será muito útil; seus signros, como na notação ecfonética e na neumática, colocados sob ou sobre as sílabas, ou ao lado dos versos, recordam o perfil básico da melodia, orientam a criança no malabarismo de se equilibrar a melodia no texto e o texto na melodia ${ }^{8}$. As entonações microtonais, típicas das fórmulas melódicas antigas e vivas no oriente e na músicas de certas nações indígenas, são típicas da melopéia infantil que ora descrevemos. Qual bardos, trovadores e aedos, as crianças criam tanto canções tonais, afinadas, quanto simulacros melódicos, como o sprachgesang de Schöenberg. Chamaram-na 
música "cantalada" (cantada + falada). Observe-se um manuscrito:

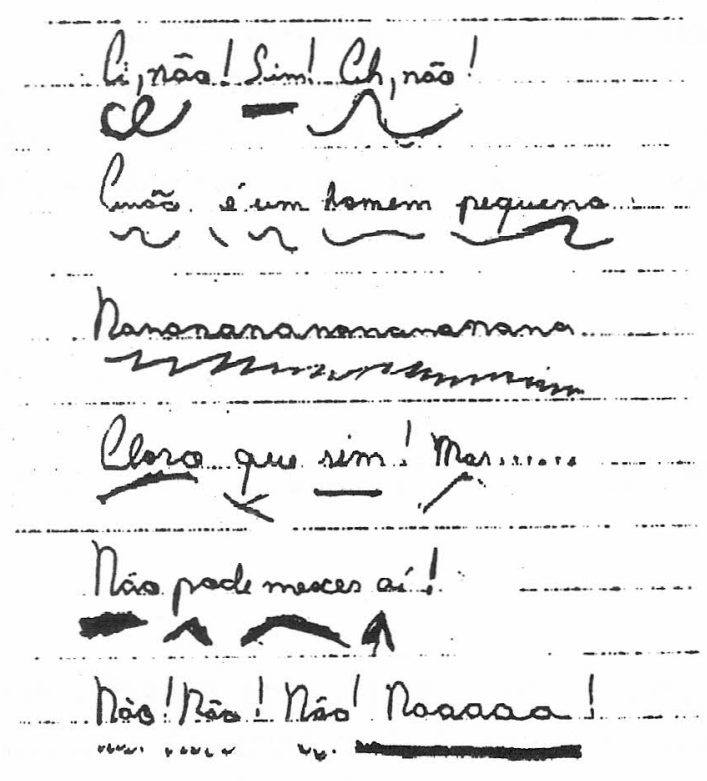

André, 8

No processo de aprendizado musical das crianças, esta notação sofrerá desenvolvimentos diferentes, mas quase sempre relacionados com o aparecimento de diagramas com linhas horizontais.

Um. deles a partir das partituras que contemplam a simultaneidade de sons: experimentando soprar em garrafas com mais ou menos água, as crianças perceberam a possibilidade de controlar as alturas. Construida a escala à la Pitágoras, passamos a experimentar as combinações de notas; as harmonias vítreas eram registradas nas partituras que estavam em uso, penas com a substituição dos boxes, pelas garrafas e suas respectivas notas.

Portanto, aqueles que antes eram boxes timbrísticos, 


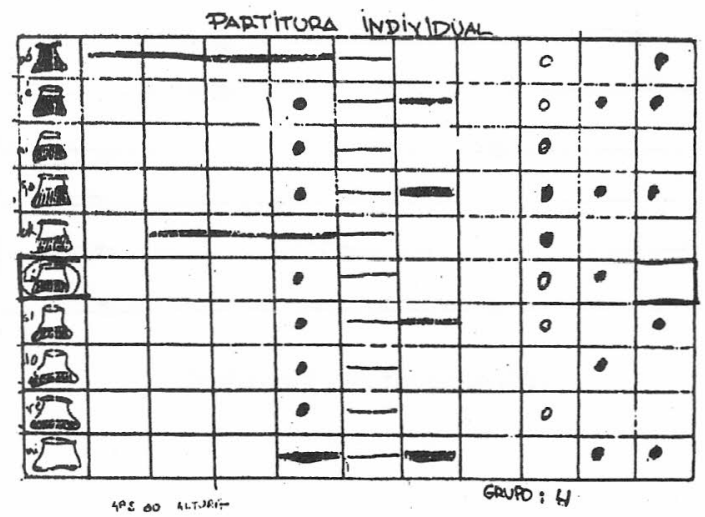

passam e ser boxes de alturas, tal como no pentagrama, mas utilizando apenas os espaços:

\begin{tabular}{|l|l|l|l|l|l|l|}
\hline$M I$ & & & & & - & 0 \\
\hline$R E$ & & & $\bullet$ & & - & - \\
\hline$D O$ & & $\bullet$ & $\bullet$ & & - & - \\
\hline$S i$ & & $\bullet$ & $\bullet$ & & - & - \\
\hline$L A$ & - & & & & - & $\bullet$ \\
\hline$S O L$ & & $\bullet$ & $\bullet$ & & - & \\
\hline$F A$ & & $\bullet$ & $\bullet$ & & - & \\
\hline$M I$ & & $\bullet$ & $\bullet$ & & & $\bullet$ \\
\hline$R E$ & & & $\bullet$ & & - & $\bullet$ \\
\hline$P O$ & & & - & & - & 0 \\
\hline
\end{tabular}

Após a experiência da leitura, extremamente dificultada pelo grande número de garrafas e pela ausência de linhas verticais sinalizadoras das imbricações de tempo, as crianças sugeriram: "A gente está registrando só nos espaços; por que não registramos também nas linhas? Assim a partitura ficaria menor e mais fácil de ler (!)" Nem precisava de tanto; o momento de introduzir a notação tradicional já era chegado, mas... assim!? Estava escrito em letras garrafais: reinventaram a pauta musical. 


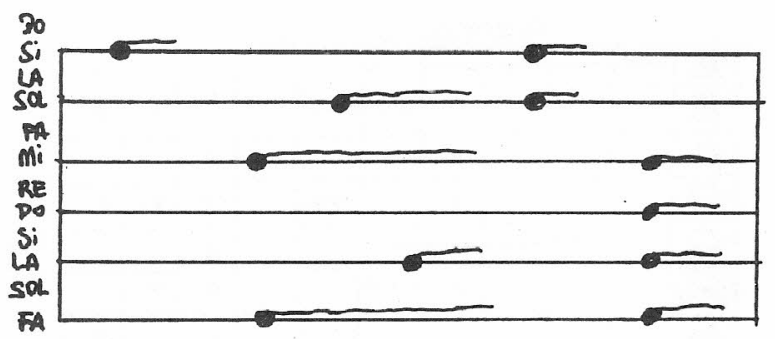

Hexagrama das garrafas ${ }^{9}$

O segundo desenvolvimento da notação analógica das crianças se deu a partir da construção do conceito de altura, articulado nas descrições do som. Vejamos como ocorreu: na descrição das alturas, as crianças de até 6-7 anos limitam-se a descrever apenas uma das relações em jogo: "é fino (agudo)", "é grosso (grave)"; não descrevem, portanto, as transformações que ocorrem no som. Mas a experiência com sons e músicas logo irá articular na criança uma conceituação, se não mais precisa, ao menos mais dinâmica. A percepção de uma frase melódica, por exemplo, não é possível por estados estanques, mas supõe uma audição global para a interiorização das relações intervalares. Se Piaget chamou a esta percepção de coordenação num sistema total ${ }^{10}$, também se pode chamá-la de uma percepção gestáltica, na medida em que só se pode chegar à compreensão de suas partes através da percepcão global da melodia e de sua estrutura. A bem da verdade, essa compreensão interna da música é muito mais completa do que aquilo que a linguagem da criança consegue descrever num primeiro momento. A evolução desta linguagem, ou seja, da consciência dos conceitos, dar-se-á na medida da evolução da prática musical e da notação. Neste sentido, o conceito de altura do som evolui para a compreensão de suas relações e das transformações; a criança, então, consegue perceber as transformações ("o som subiu", "...ficou agudo") e as relações ("... é mais grave", "o outro é mais fino"), possibilitando a seriação do som em diferentes alturas, desde o 
mais grave até o mais agudo. Nas primeiras seriações de alturas, a criança define o grave, o médio e o agudo.

Tal conceituação da altura resultará em dois tipos de elementos gráficos: uma notação alfabética e uma diastemática. Esta última, oriunda da divisão do campo da altura em três regiões (agudo, médio e grave), expressa-se na constituição de um diagrama de três linhas precedido de uma clave composta dos signos "a", "m" e "g". Eis a invenção, nas versões de duas turmas:

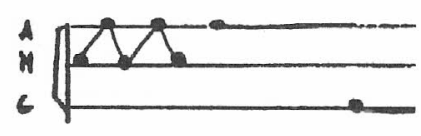

Rodrigo, 10

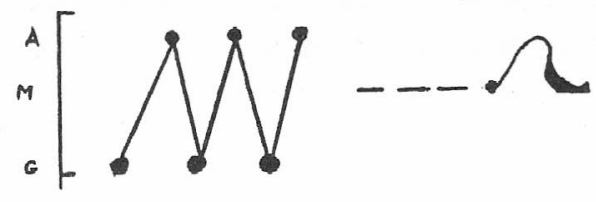

Fernanda, 9

O aparecimento das linhas na notação analógica (o trigrama) confirma sua característica diastemática e define, no tabuleiro das alturas, referências genéricas (a clave " $a$ ", "m", "g") para a articulação dos sons, quase tão genéricas quanto as da notação medieval quando do aparecimento da primeira linha:

“(...) Desde o século XI, encontramos manuscritos munidos de uma linha traçada, freqüentemente colorida de vermelho, particularmente na Itália. A partir do século XII, acrescentaram-se uma linha amarela e também uma linha verde. No início da linha vermelha, era comum colocar-se a letra " $F$ " (fa) e na cabeceira da linha amarela ou verde a letra "c" (do). (...) O número de linhas variou por muito tempo, oscilando (principalmente) entre uma e sete"."1

As claves, as linhas e as cores definiam, assim, as referências da alturas. Uma observação de Guy d'Arezzo nos faz reconhecer sua utilidade para a prática musical: 
"(...) É porque, mesmo se a localização de cada neuma é perfeita, ela não tem nenhuma significação e permanece sem valor sem a adjunção das letras (claves) ou das cores. Empregam-se com efeito duas cores, o amarelo (açafrão) e o vermelho, cores por meio das quais eu the forneço regras muito úteis". 12

Após algum tempo de uso do trigrama, as crianças, então com 9 anos, defrontaram-se com o desafio de utilizá-lo no registro de composições para flauta doce. Notem-se atentamente alguns manuscritos resultantes:
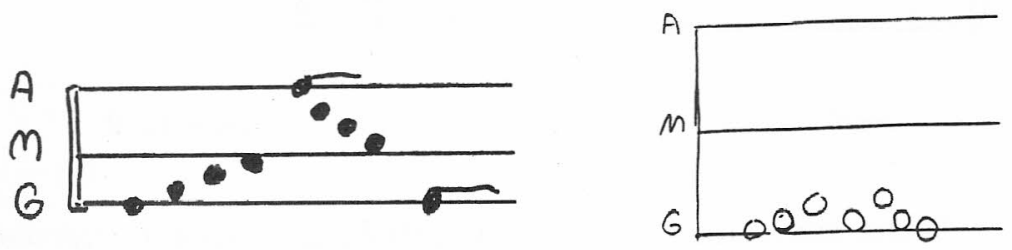

Ditado no trigrama

Como se vê, os sons, antes registrados unicamente nas linhas, passam a ocupar também os espaços. Esta mudança se decorre do fato de que a flauta recorta o contínuo das alturas em muitas notas, tornando as referências grave, médio e agudo insuficientes para sua representação. A propósito disso, leia-se uma crônica de 986 , em que um abade de Corbie comenta uma passagem de outro cronista, do monastério de Paris:

“(..) Nesta época, introduziu-se em nosso monastério uma nova maneira de cantar, por meio de curvaturas e de signos separados por linhas e espaços; este sistema permite transcrever os sons de maneira um pouco mais precisa que antes ; pois não existia linha alguma nos antifonários e nos graduais de nossa igreja"13. 
Mas há um outro desdobramento do trigrama das crianças:
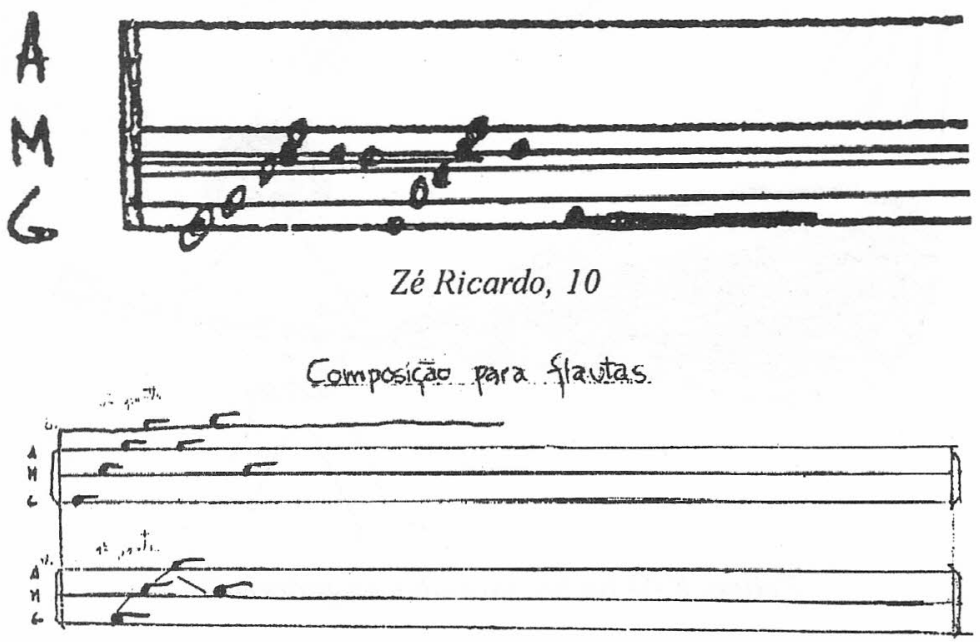

Alê, 10

$\mathrm{Na}$ busca de uma pauta adequada à representação de uma variedade maior de alturas, linhas suplementares são acrescentadas ao trigrama . Mais uma vez, a pauta reinventada. ${ }^{14} \mathrm{E}$ as claves, antes genericamente definidas por "a", "m" e "g", agora são definidas por notas, tais como as claves tradicionais, inicialmente numa escolha arbitrária de cada criança compositora.

Assim, com os diagramas raiados para a representação das alturas, a notação analógica se depura e se torna precisa. Embora as crianças tenham dado ainda outras soluções gráficas para a questão das alturas precisas e recortadas do contínuo, estas que foram apresentadas parecem ser representativas, no sentido em que não só mostram a construção gradativa de conceitos musicais, mas também se aproximam das soluções historicamente definidas.

Se a exemplo da chamada cisão do Oriente, onde até hoje são utilizados os neumas sem linhas, houve certos grupos de crianças que não chegaram aos diagramas, a aquisição do conceito de altura definida foi desenvolvida e garantida por outros meios. 


\section{O TIMBRE: cor e textura}

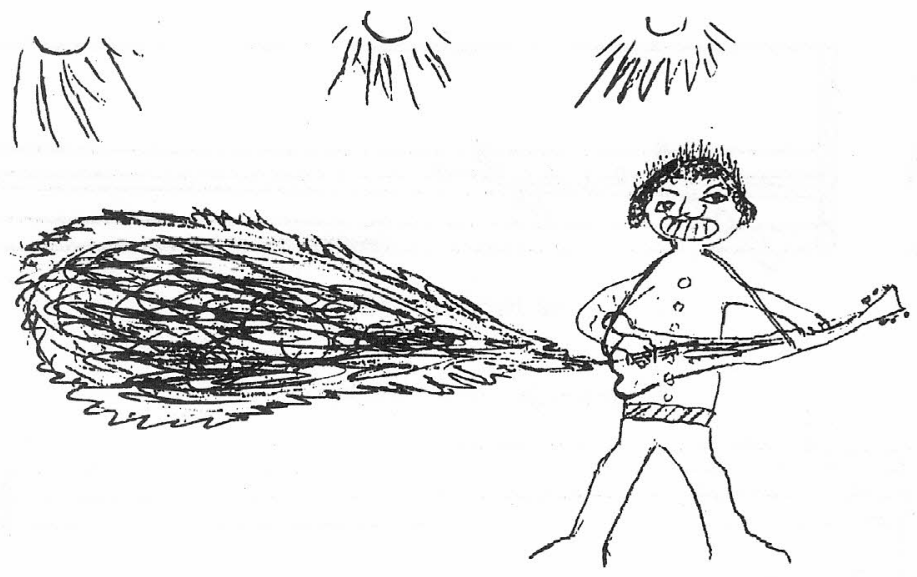

Felipe, 8 (O timbre do ruido da guitarra:)

É um forte índice de ruído, a textura gráfica resultante de um traçado tipo "dente de serra", tal como no último exemplo. A concepção deste tipo de grafía ocorre tanto a partir de uma imitação motora - em que os movimentos gestuais de um violonista, por exemplo, a friccionar rapidamente as cordas com suas unhas, motivam a criança a realizar o mesmo movimento na produção da grafia - quanto a partir de uma imitação sonora mesmo - pois o som do lápis friccionando rapidamente o papel produz, além da tal textura gráfica, também um ruído. Este é um dos primeiros tipos de grafia analógica que a criança produz, e o faz com certa facilidade; ela pode mesmo identificar, a partir desta grafia dada, suas possíveis fontes sonoras, mostrando que, além da imitação motora e da imitação sonora, isto é, além da percepção, a criança se utiliza da função semiótica para relacionar som e grafia. Neste sentido, observemos as hipóteses das crianças:

Pergunta: "Adivinhe que bicho faz este som:

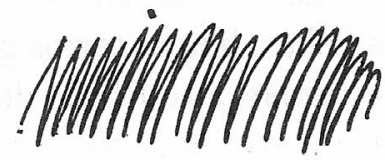


Respostas de cento e dez crianças de 7 a 9 anos:

Felino chiando (pantera, lince, jaguatirica, onça, tigre, leopardo e leão) - 55 respostas
Mosquito zumbindo -25 respostas
Carneiro balindo -15 respostas
Cascavel com seu guizo - 10 respostas
Grilo cricrilando - 5 respostas

Como se vê, no timbre vive também o ruído, o enfant terrible da música, a "orelha" negra da família. Na Grécia antiga, o ruído era às vezes idolatrado: a cigarra, em função de seu belo ruído, era adorada pelos gregos que a consagravam a Apolo. Já na Idade Média, desempregado, o ruído vivia nas ruas com a música profana, principalmente nos instrumentos; hoje, mesmo inserido na música erudita, desde Varèse, Bartók e Stravinsky, ainda se sente mais à vontade na música popular, em especial no rock, onde foi levado às últimas conseqüências no grito primal do Blues e do Rock e na "harpa farpada" de Jimmi Hendrix. ${ }^{15}$

Não é possível falar de timbre sem falar dos instrumentos musicais, já que estes são a prova mais contundente do desejo do homem de buscar sempre novos timbres para sua paleta musical. As cordas, as percussões, os sopros se dividem em outras categorias em face a essa diversidade. Ainda hoje, quando parece que tudo já foi inventado, há uma infinita gama de timbres sendo produzida. No trabalho com as crianças, os timbres também são buscados além das fronteiras dos timbres dados: saímoš ao aberto à caça de novas sonoridades e também construímos timbres à imagem de instrumentos imaginados.

A notação musical para os instrumentos teve, ao longo da história da música, caracerísticas e sistemas próprios e particulares que a diferenciavam da notaçãò eminentemente vocal. $\mathrm{Na}$ Grécia, as primeiras tentativas de notação musical para instrumentos, no caso para o aulos, instrumento de sopro, se atribuem 
a Polymnesto de Colofón no séc. VII a.C. ${ }^{16}$ Se no início os instrumentos eram subordinados à voz e ao acompanhamento do canto, a arte de tanger a cítara progrediu consideravelmente com Thámyris, de quem se disse que "se atreveu a tocá-la independentemente da voz" 17 . Se este pequeno esboço histórico traz à luz a idéia de uma notação especial para o instrumento, esta não se dá tanto em função do timbre diferenciado de seu material, mas porque sua mecânica e sua digitação deveriam ser muito mais detalhadas do que, no início, os melismas da voz, que acontecem internamente ao homem e que seriam conduzidos mais por uma intuição. A externalidade do instrumento, que tem graduações desde o sopro até a percussão, foi responsável por avanços na notação; sua contribuição só não foi maior porque, durante quase toda a Idade Média, esteve excluído dos cultos onde a música e a notação se desenvolviam.

Diferentemente das outras características do som, altura e intensidade, e mesmo da própria duração, o timbre não acontece num contínuo e não se compreende por uma seriação (como mais ou menos grave - na altura -, mais ou menos forte - na intensidade -, mais ou menos longo - na duração); ele se caracteriza na verdade por sons discretos formados, à semelhança das cores, pela composição reticular de harmônicos. $\mathrm{O}$ que se pode dizer é que os timbres são regidos por infinitos contínuos discretos: mais ou menos "escuro", mais ou menos "metálico", mais ou menos "rouco", mais ou menos "abafado", etc. Às crianças interessa como conseguir um determinado timbre, ou melhor, como atingir e conservar alguns destes contínuos. Da prática elas chegam a duas hipóteses complementares: que o timbre se consegue pelo material sônico (fonte sonora) e pela maneira de acioná-lo (o homem e a técnica). Assim como se costuma emprestar ao timbre o termo "cor" ("Klangfarbe", ou seja, cor do som), referenciado ao material da fonte sonora, assim também se pode emprestar o termo "textura", referenciado ao resultado sonoro da técnica de acionamento e ao som no tempo. 


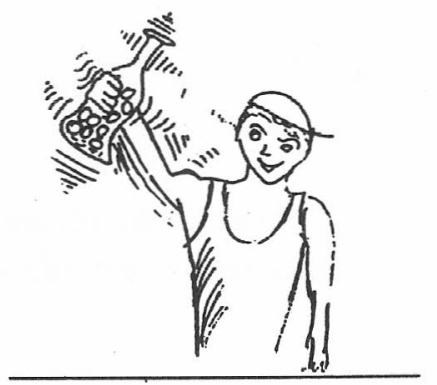

Fábio, 10

(desenho da fonte sonora - vidro)

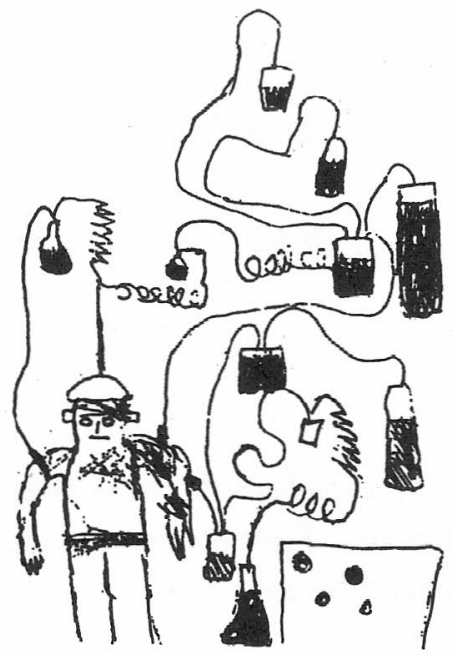

Rodrigo , 7 (desenho de imaginação: Webern e sua Klangenfarbenmelodie "melodia de timbres")

Se o timbre pode ser entendido concretamente como a dimensão do som que resulta da matéria física colocada em vibração e da forma como esta vibração foi provocada, resta ainda sua condição interna, sua retícula, como dissemos, que são combinações de micro-alturas: os chamados harmônicos. O timbre é, pois, o resultado de somatórios, de misturas químicas; daí a nítida sensação de se "ouvir" nos timbres as cores e seus matizes, e é por isso que Klee via música nas transparências da aquarela.

Se essa idéia de um timbre visual não resultou em notação na história da música, já na grafia das crianças aconteceu o contrário. Uma abundância de relações visuais e plásticas se dá no processo de codificação dos sons. Imagens, cores e texturas: signos motivados; formas geométricas e diagramáticas: signos motivados e signos arbitrários. Como exemplos, tem-se uma coleção dos signos geométricos mais utilizados, emblemas da diferença: 


\begin{tabular}{|c|}
\hline $.0 \bullet \cdot \Delta \Delta \square \square \square \triangleright \bullet$ \\
\hline 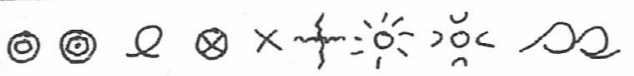 \\
\hline 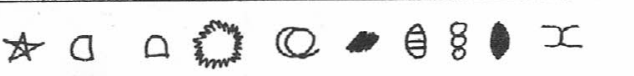 \\
\hline
\end{tabular}

E até o solfejo de timbres era trabalhado em músicas vocais, em que a voz funcionava como um instrumento, isto é, em músicas vocais diferentes de canções:

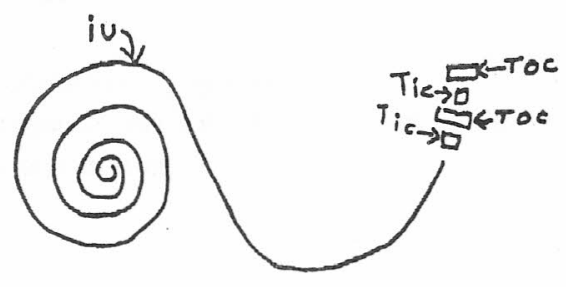

Patricia, 8 (signos analógicos geométricos reiterados por onomatopéias)

O timbre, nas partituras mais evoluídas das crianças, estará representado de duas maneiras: por descrição (do timbre ou instrumento) no começo de cada box (pauta) e por uma diferenciação na forma dos signos, funcionando como "marcas de identificação":

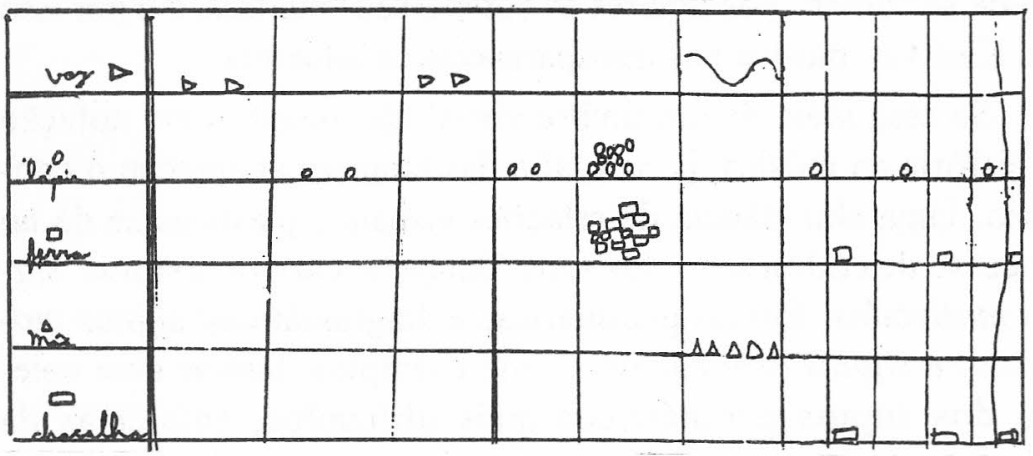

Ana Paula e Daniel, 8 


\section{Conclusão}

Se é na percepção dos sons e no contato com os métodos gráficos dos colegas que as escolhas gráficas se iniciam, será também nas composições musicais feitas em pequenos grupos, e coletivamente, que essas escolhas tomarão impulso definitivo, pela necessidade premente de um repertório comum para a criação musical; é, pois, o processo de composição que articula e estrutura a multiplicidade das manifestações musicais. Assim, as escolhas gráficas, no início setorizadas, formam pequenos "dialetos" semiográficos: um grupo faz música em quadrinhos desenhados, outro faz roteiro descritivo, outro usa notação analógica e um outro usa notação mista. A capacidade da criança em estabelecer convenções e regras, notadamente a partir dos 7 anos de idade, possibilita que, com a socialização crescente das soluções gráficas para os sons, a sistematização avance até uma convenção coletiva. Tal processo depende da evolução da prática musical como um todo.

Por esta razão, a notação nunca está definitivamente pronta enquanto código. Ela se transforma em adaptações constantes às demandas da composição, da percepção, da prática musical e da compreensão e construção de conceitos; ela se transforma também em função das demandas históricas e sociais de cada grupo, seja àquelas relativas à faixa etária ou época histórica, seja às relativas à sua cultura ou modo de produção. É a evolução coordenada destes fatores que permite a articulação dos possiveis em necessári$o s$, ou seja, que a experiência se torne sistema; pois, se nunca há um código pronto mas sim códigos em movimento, percebe-se, ao mesmo tempo, uma nítida direcionalidade no processo de aprendizagem, um desenvolvimento convergente da notação dos diferentes grupos e gerações de crianças que participaram deste trabalho, desde a pluralidade até um sistema típico.

A passagem de uma música simbólica e referenciada a seus dados visuais - fonte sonora e imaginação - para uma música lúdica, referenciada aos próprios sons em jogo, também é nítida nas grafias: no início com predomínio da pictografia e do uso da linguagem, 
evolui para um predomínio da notação plástica e analógica. Esta evolução nem sempre é linear ou em bloco; a propósito disso, comparem-se os resultados de um ditado sonoro nos quais se percebem diferentes etapas da grafia ocorrendo paralelamente. $\mathrm{O}$ dictante produziu a seguinte sequuência de sons: uma batida, um silêncio, três batidas, um silêncio, um assobio descendente em glissando e, finalmente, uma batida mais forte que as anteriores.
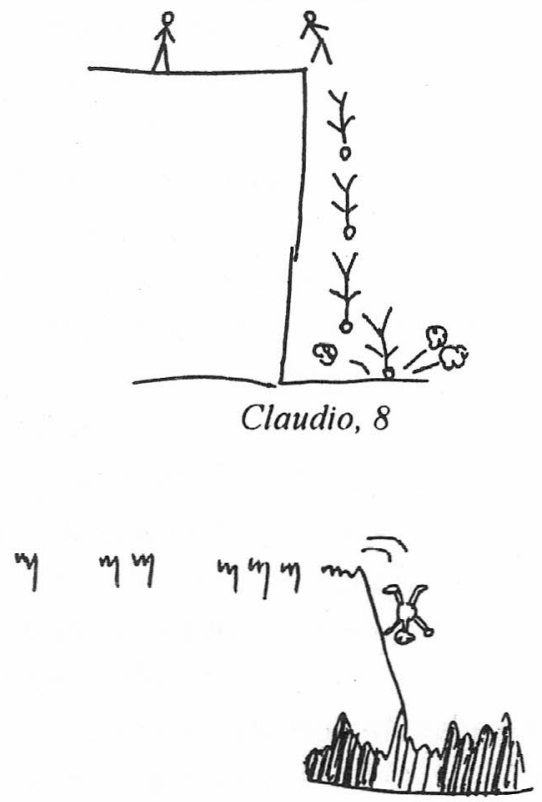

Jetra, 8

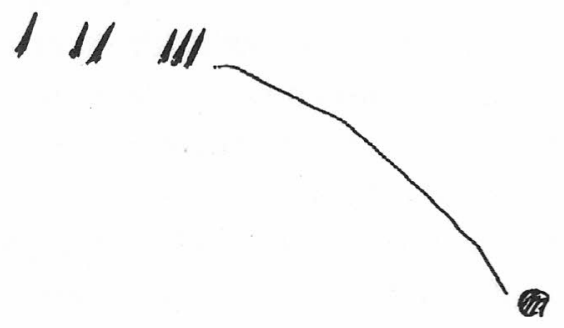

Nina, 8 
A pictografia e a linguagem irão inserir-se na notação analógica enquanto signos acessórios ou auxiliares. Na verdade, desde o início que se delineia uma notação mista: inteligentemente, as crianças experimentam diferentes encaixes funcionais entre os tipos de signo, buscando um encaixe ideal; nestes encaixes, ora predomina um tipo, ora outro, até que os signos analógicos sejam escolhidos. A mobilidade dos signos analógicos na representação do tempo e dos parâmetros do som e a possibilidade de sua leitura sem mediação de abstrações - como nos desenhos da fonte sonora e nas descrições - determinam esta escolha; sua concisão e eficácia se evidencia para as crianças nos trabalhos de composição e nas leituras constantes das performances.

Combinada a elementos diagramáticos, a notação analógica irá atingir um alto desenvolvimento na representação das alturas; já na representação das intensidades, a notação analógica irá, com simplicidade comparável à da notação ocidental da primeira metade do século XIX, chegar a resultados suficientes para uma leitura satisfatória; enquanto que na representação do timbre, será com as cores, texturas e com os signos analógicos fechados (ou geométricos) que a notação das crianças irá, sem atingir um aprimoramento em termos de alta precisão, ao menos colecionar uma enorme gama de elementos gráficos.

Estas escolhas não chegam, no início, a se constituir como código, mas muito mais como método. Assim, a evolução gráficomusical da criança se cadencia em uma sucessão de estados em transformação: com variados métodos de grafar e, antes, de imaginar o som, a criança modula-os à sua vontade e de acordo com seu desenvolvimento cognitivo. Em uma palavra, a produção de grafias aí constitui um instrumento epistêmico de importância considerável no processo de construção do conhecimento.

\section{NOTAS}

1. Cabe aqui esclarecer que o termo "notação musical" não deriva diretamente do termo "nota musical", mas sim de uma "nota" genérica, que 
tem sua raiz na nota, do latim, que significa "sinal gráfico de apoio mnésico", que deu notatio, que significa "sistema de sinais gráficos convencionados (signos)". Portanto, quando falamos aqui em notação musical, estamos nos referindo a uma notação musical no sentido lato, e não à notação ortocrônica ocidental, chamada notação tradicional, universal e, muitas vezes, no sentido estrito, musical.

2. Piaget diferencia e define simbolo e signo em seu La Naissance de l'inteligence chez l'enfant (Neuchâtel, Delachaux \& Niestlé, 1959, p. 70 ), onde diz "símbolo e signo não são senão os dois pólos, individual e social, de uma mesma elaboração de significações".

3. Ley Semyohovich VYGOTSKY, A Formação Social da Mente, $3^{\mathrm{a}}$ ed., São Paulo, Martins Fontes, 1989, p. 119.

4. Jean PIAGET, Psicologia da Criança. São Paulo, Difel, 1982. p. 52.

5. Frederick DORIAN, História de la Música a través de su ejecución, Buenos Aires, Editorial Schapire, 1950. p. 143.

6. Até o século dezoito, o eco era uma lei não escrita da interpretação da dinâmica, de modo que todas as frases repetidas eram executadas habitualmente piano.

7. Armand MACHABEY, La Notation Musicale, Paris, Universitaires de France, 1952, pp. 27-29.

8. Luiz TATIT, O Cancionista - Composição de Canções no Brasil, São Paulo, Edusp, 1986. p. 9.

9. Sobre a quantidade de linhas, Tappolet nos conta que o autor do célebre tratado Musica enchiriadis empregou uma pauta com 18 linhas; Guy d'Arezzo se limitou a quatro, mas utilizou também os espaços; Oswald Koller publicou uma composição com 15 linhas azuis e 9 vermelhas, total: 24 linhas; Bellerman empregou 10 linhas e utilizou seus espaços. Desde o início do século XIII, os espanhóis fizeram uso da pauta de cinco linhas, o pentagrama. Willy TAPPOLET, La Notation Musicale et son influence sur la Pratique de la Musique du Moyen Age a nos Jours, Genève, A la Baconnière, 1947. p. 34

10. PIAGET, O Desenvolvimento das Quantidades Físicas na Criança, p. 42.

11. TAPPOLET, p. 33-34. Parêntesis nosso.

12. Idem, p. 35.

13. Idem. p. 33.

14. Com relação à flauta e à sua influência neste processo, é interessante notar que as primeiras notações gregas, com Polymnasto de Colofón, até meados do século VII a.C., e com Sákadas, meio século mais tarde, tinham sua aplicação no aulos (flauta), sobretudo para imitar nele uma melodia vocal forasteira, o que torna compreensível a eficácia da notação na qualidade de ajuda mnemotécnica. Em todo caso, o progresso da notação grega coincidiu com o auge da prática do aulos em Atenas e com 
a formulação de uma doutrina teórica com Lasos de Henrique, que foi um auletista notável. Conf. Adolfo SALAZAR, La Música en la Cultura Griega - Teoría y Prática de la Música a Través de la História.México, El Colegio de Mexico, 1954, vol.1, p. 119.

15. José Miguel WISNIK, O Som e o Sentido - uma outra história das músicas, São Paulo, Companhia das Letras, 1989. p. 43.

16. Idem, p. 41.

17. Idem, p. 47.

Pedro Paulo Salles é professor do Departamento de Música da ECA-USP. 